\section{Tough Decisions}

John M Freeman and Kevin McDonnell, 181 pages, Oxford, £22.50, Oxford University Press, 1987.

This book consists of 12 chapters, each devoted to an ethically difficult case. These are followed by a brief introduction to the basic concepts of medical ethical analysis and a chapter arguing that a good ethical decision is characterised not by the decision itself but by the process used to reach it.

The case-based approach to the teaching of clinical ethical decisionmaking is now commonplace, and there are a number of books which analyse the ethical issues, in real or realistic cases. What is original in this book is the attempt to go beyond this and to place the reader in the position of one of the participants in a 'tough decision'. The authors state that their presentation is modelled on that of the popular 'adventure books' where at various points in the story the reader makes a choice on behalf of the hero, and this choice then determines subsequent events. Unlike adventure books, however, the reader is exhorted to stop and justify the decision made, and to comment on various aspects of the ethical issues raised. The precise structure of the chapters varies and not all the cases use the adventure book format. The simplest is just a scenario with a list of questions and 'things to do' arising from it at the end, a modified version of a traditional textbook format; whilst other are more truly adventures, with a complex branching structure where there are three or four stages of choice which determine the future.

The cases are well written in an informal but elegant prose style, and the situations and characters are outlined well. Particularly appealing is the candour with which the health professionals involved are portrayed.
Often in ethical discussions doctors appear as shadowy, platonic figures making totally intellectual decisions on the basis of clear and reasoned arguments. In contrast the people who appear in these cases are real flesh and blood. Personalities such as the zealous registrar with tunnel vision, obsessed with applied physiology but unconcerned with the human and social implications of his actions, and the arrogant consultant whose actions seem to be motivated more by a desire for fame and fortune than the patient's well-being will be well known to anyone familar with teaching-hospital life. I look forward to reading the authors' first novel!

The choice and range of the cases is less satisfactory. There are eight cases which concern children, one about genetic counselling, and the remaining three deal with adult cases. It is therefore difficult to see for whom the book is appropriate. If it is intended for specialist doctors, nurses and others working with children then the reason for including a case on the right to die and living wills in an elderly patient seems unclear. If, however, it is intended for a wider audience, such as medical or nursing undergraduates, or general or family physicians, then too much time is spent in the neonatal intensive care unit, to the detriment of other areas. In particular there are no cases from reproductive medicine perhaps currently the prime area for tough ethical decisions. Also, although it may be unfair to criticise authors for writing to their title, it would have been nice to have seen one or two cases where the ethical decisions to be made were a little less likely to make tabloid headlines. Medical ethicists are as prone as high-tech clinicians to an obsession with the sensational and the 'interesting case', to the detriment of proper consideration of more common problems which may be important to many more people.
Another difficulty paradoxically arises because of the authors' success in their objective of creating realistic situations. The great detail which they provide inevitably includes much that is culturally specific, and this limits the range of application of their work. Although the basic clinical situations and ethical dilemmas are universal, the context of their stories is particularly American. The organisation of hospitals, the financing of the health service, and the legal framework in which clinical activity must take place differs considerably between countries and it would probably therefore be difficult for a paediatrician working outside the USA to identify with many of the situations which are outlined. This is of course not wholly a disadvantage - recognising the extent to which our attitudes are determined by the cultural and legal framework in which we work is itself ethically interesting. For instance to the British clinician the opportunity to relate to a clinical ethics committee (unknown in this country), even if only in imagination, is a fascinating experience. It does however make it harder for the non-American student to link the stories in the book to his or her own clinical experience.

Thus, although I enjoyed this work, I am unsure what place it will find in the literature of ethics teaching. I fear only the most disciplined student, if working alone, will use it as intended pausing to write letters to congressmen, drafting reports for ethical committees, and marshalling detailed ethical defences for his or her conclusions. Much of the material would be excellent for undergraduate or postgraduate courses, though here the skewed selection of material and the crosscultural problems will make it an occasionally useful resource rather than the core text it might otherwise be. Despite these weaknesses it is a valuable contribution and anyone interested in 
or teaching paediatric ethics would be well advised to consider this book carefully.

DR PETER D TOON

General Practitioner 206 Queensbridge Road, London E8

\section{Reproductive Genetics and the Law} S Elias, G J Annas, 323 pages, Chicago, London, Boca Raton, £22.75, hbk, Year Book Medical Publishers Inc, 1987.

There is a rapidly increasing range of techniques for prenatal detection of genetic diseases and a rapid increase in the number of conditions which may be so detected. Similarly, therapeutic procedures of varying degrees of effectiveness and acceptability are continually being added to the medical repertoire. The methods of regulating reproduction by manipulating fertilisation and the early embryo are used to bypass human infertility and to make transgenic animals. All these technical developments have potential effects on human reproduction and development, make it possible to have choices with regard to particular genetic diseases or fetal damage and clearly have ethical and legal implications. Finally the number of drugs, industrial and agricultural products which may be teratogenic to the human fetus is also increasing beyond the capacity for testing. The rights and needs of society, the family, the mother, and the fetus differ, and may even be in apparent opposition, so that some basis for evaluation and decision is required.

Some knowledge of genetics and medical techniques is necessary for lawyers and legislators, and some knowledge of the law for genetic counsellors, researchers and scientists concerned with resource allocation. Professors Elias and Annas represent medical genetics and health law respectively, and their book offers a sustained and solid effort to appraise and educate. The book is enjoyably lucid throughout and covers a wide range of theoretical and technical matters. It deals with fundamental aspects of DNA structure and replication, meiosis, chromosomal behaviour and defects, genetic segregation, and the response to teratogens. It deals with screening, counselling, (and sensitivity to clients) prenatal diagnosis, embryo transfer perinatal surgery, and methods of inserting genes into eggs or cells. It also deals with legal problems involved in counselling, abortion and treatment; analysing and commenting on case law and on the problems involved and it discusses quality of life criteria, relative risks and conflict of rights.

It must seem ungrateful to wish that some problems which are touched upon too briefly or not at all had been discussed more fully. Since the main issues of the book all touch upon human need and human suffering and since the quality of life argument is an important part of the debate, (relevant to abortion versus treatment for example) then a better discussion of therapy would be in order.

Therapy is possible, in principle, for many metabolic diseases. It is less likely for those involving brain cells directly and seems unlikely for defects in structural proteins such as the collagen disorders.

Specific dietary restrictions are outlined briefly for three genetic conditions, and perinatal surgery for a few more. Nothing is said of unpleasant treatments which may prolong life for a time, but are palliative only; for example, weekly blood transfusions and daily injections of an iron-chelating agent for thalassemia. The quality of life is also affected by conditions which are not lethal for infants but which lead to severe pain such as sickle cell anaemia or Fabry's disease.

Changes to brain function may occur at teratogen levels too low to cause visible morphological change. A potentially normal fetus is irreversibly damaged in a phenotypically rescued mother homozygous for PKU, but the treatment they suggest is not properly tested and in any case prevention of microcephaly would not exclude possible deficits in intelligence and behaviour. With respect to industrial teratogens, exposure of a population may require wholesale offers of abortion to all pregnant women, as at Seveso.

More discussion on late onset genetic diseases would be valuable. An infant with Tay-Sachs will be soon dead, one with Duchenne muscular dystrophy will survive for several years, and Huntingdon's Chorea typically has a late onset. Arguments based on the number of valuable years of life must consider temporal gradations but the subjective experience of life before and during the degenerative period and the impact on the family also needs to be considered.

There is only a brief mention of resource allocation, yet decisions in this area may have an enormous effect on most of the issues discussed.

I hope that someone will write a book as clear and pleasant to read as this one, to illuminate English and Scottish laws, as this one has, for me, illuminated American law.

There is a reasonable index, a good list of chapter references and several useful tables.

R M CLAYTON Reader Department of Genetics University of Edinburgh West Mains Rd Edinburgh EH9 37N

\section{Saggi di Medicina e Scienze Umane}

(Published in Italian) E Mascitelli, A Ponsetto, N Luhmann, M G Lombardo, H J Helle, R Contardi, 339 pages, Milano, Lire 30,000, Istituto Scientifico S Raffaele di Milano, 1984.

The essays collected in this book were presented as lectures delivered at an experimental course held at the University Hospital S Raffaelle in Milano (Italy) in the academic year 1982-83. The aim of the course was to include some teaching of humanities in the curriculum of the Faculty of Medicine and this book is interesting as it represents a Catholic proposal to deal with this matter. Papers included are of different quality but all of them try to widen the horizon of medicine in the attempt to 'humanise' the general perspective. This approach is similar to the one advanced by E D Pellegrino and his group in the English-speaking world.

In this review, I shall focus my attention on N Luhmann's paper as it is the most interesting one and provides a good insight into the book's objectives.

According to Luhmann's systemic functionalism, society is an articulation of different partial systems. These partial systems are autonomous and independently developing. Medicine is one such partial system, with its own unique feature.

According to this view when a functional system has routine questions to answer the system is self-sufficient and can provide the decision using its own rules.

But when the (partial) system has to face exceptional questions then such 